San Jose State University

SJSU ScholarWorks

Faculty Publications, Anthropology

Anthropology

8-1-2009

\title{
Paleoepidemiological Patterns of Interpersonal Aggression in a Prehistoric Central California Population from CA-ALA-329
}

\author{
Alan M. Leventhal \\ San Jose State University, alan.leventhal@sjsu.edu \\ Robert Jurmain \\ Eric Bartelink \\ Viviana Bellifemine \\ Irina Nechayev
}

See next page for additional authors

Follow this and additional works at: https://scholarworks.sjsu.edu/anth_pub

Part of the Anthropology Commons, and the Urban Studies and Planning Commons

\section{Recommended Citation}

Alan M. Leventhal, Robert Jurmain, Eric Bartelink, Viviana Bellifemine, Irina Nechayev, Melinda Atwood, and Diane DiGiuseppe. "Paleoepidemiological Patterns of Interpersonal Aggression in a Prehistoric Central California Population from CA-ALA-329" American Journal of Physical Anthropology (2009): 462-473. https://doi.org/10.1002/ajpa.21002

This Article is brought to you for free and open access by the Anthropology at SJSU ScholarWorks. It has been accepted for inclusion in Faculty Publications, Anthropology by an authorized administrator of SJSU ScholarWorks. For more information, please contact scholarworks@sjsu.edu. 


\section{Authors}

Alan M. Leventhal, Robert Jurmain, Eric Bartelink, Viviana Bellifemine, Irina Nechayev, Melinda Atwood, and Diane DiGiuseppe 


\title{
Paleoepidemiological Patterns of Interpersonal Aggression in a Prehistoric Central California Population From CA-ALA-329
}

\author{
Robert Jurmain, ${ }^{1 *}$ Eric J. Bartelink, ${ }^{2}$ Alan Leventhal, ${ }^{1}$ Viviana Bellifemine,${ }^{3}$ Irina Nechayev, ${ }^{1}$ \\ AQ1 Melynda Atwoodw, ${ }^{1}$ and Diane DiGiuseppe ${ }^{1}$ \\ ${ }^{1}$ Department of Anthropology, San Jose State University, San Jose, CA 95192-0113 \\ ${ }^{2}$ Department of Anthropology, California State University, Chico, CA 95929-0400 \\ ${ }^{3}$ Department of Archaeology, University of Cambridge, Cambridge CB2 3DZ, UK
}

\section{KEY WORDS aggression; craniofacial injury; projectile injury; temporal patterns}

\begin{abstract}
Interpersonal aggression is assessed paleoepidemiologically in a large skeletal population from the CA-ALA-329 site located on the southeastern side of San Francisco Bay, California. This comprehensive analysis included all currently recognized skeletal criteria, including craniofacial fracture, projectile injury, forearm fracture, and perimortem bone modification. Craniofacial injury is moderately common, showing an adult prevalence of $9.0 \%$ with facial lesions accounting for $>50 \%$ of involvement. Clinical studies suggest that such separate evaluation of facial involvement provides a useful perspective for understanding patterns of interpersonal aggression. In this group male facial involvement is significantly greater than in females, paralleling the pattern found widely in contemporary populations as well as in African apes. When compared to other North American skeletal samples the prevalence of adult cra-
\end{abstract}

Aggression and violence are not uncommon among mammalian species and have been especially well documented among our closest primate relatives (Lovell, 1991; Jurmain, 1997). Warfare in humans obviously intensifies both the frequency and intensity of interpersonal aggression, and such seemingly self-destructive behavior is thought to have been very common throughout human history (Keeley, 1996). But even such supposedly distinctive organized violence is not entirely unique to our species (Goodall, 1986; Wrangham and Peterson, 1996).

Skeletal data derived from archaeological contexts provide an especially rich resource to investigate the nature and frequency of interpersonal aggression in prehistory (Lambert, 2002). Much of the paleopathological literature has focused primarily on descriptive analysis, but there are some outstanding early examples of a more population-based approach to understanding skeletal trauma (most notably, Wood Jones, 1910).

More recently, paleoepidemiological assessments of skeletal trauma have become more systematic (Lovejoy and Heiple, 1981; Webb, 1995; Grauer and Roberts, 1996; Kilgore et al., 1997; Judd and Roberts, 1999; Judd, 2002, 2004). Several contributions have concentrated more specifically on probable evidence of interpersonal aggression (Walker, 1989; Smith, 1996, 1997, 2003; Lambert, 1994, 1997; Jurmain and Bellifemine, 1997; Ogilvie and Hilton, 2000; Standen and Arriaza, 2000; Dawson et al., 2003; Willey and Emerson, 1993; Williamson et al., nial vault injury $(3.3 \%)$ and especially projectile injury $(4.4 \%)$ are quite high. However, well documented populations from southern California show markedly higher prevalence for both types of skeletal markers of aggression. Forearm fracture is also assessed using a rigorous radiographic methodology and results suggest that these injuries are not reliable indicators of interpersonal aggression. Lastly, perimortem bone modification was not observed in this population, although it has been recorded from other (older) sites nearby. This study provides an evaluation of multiple skeletal markers of interpersonal aggression in the largest sample from a single site yet reported in North America and, joined with consideration of cultural context, helps further illuminate both geographic and temporal patterns of interpersonal aggression in California. Am J Phys Anthropol 000:000000, 2008. ๑ 2008 Wiley-Liss, Inc.

2003; Lessa and Mendonça de Souza, 2004; Judd, 2006, 2008; Roksandic et al., 2006; Torres-Rouff and Costa Junqueira, 2006; Buzon and Richman, 2007; Tung, 2007; Steadman, 2008).

In the present study we report on skeletal evidence of interpersonal aggression from a large, well-preserved skeletal collection from the CA-ALA-329 site in central California. This site is of particular note, since it represents one of the largest curated collections from a single site in the western US. Moreover, owing to carefully controlled excavations, archaeological context is well documented and includes a wealth of grave-associated artifacts.

Traumatic involvement and some aspects of interpersonal aggression at this site have been previously reported (Jurmain, 1991; Jurmain and Bellifemine,

Grant sponsor: College of Behavioral and Social Sciences Strategic Performance, California State University, Chico.

*Correspondence to: Robert Jurmain, Department of Anthropology, San Jose State University, San Jose, CA 95192-0113, USA. E-mail: rjurmain@email.sjsu.edu

Received 2 February 2008; accepted 4 November 2008

DOI 10.1002/ajpa.21002

Published online in Wiley InterScience

(www.interscience.wiley.com). 
1997). Further access to a significant new portion of the sample as well as more recently published approaches for assessing interpersonal aggression warranted a comprehensive and much expanded reanalysis.

First, we recently had the opportunity to analyze additional skeletal material from the site $(N=61$ individuals) curated at the University of California, Berkeley (UCB). Second, more recent publications emphasizing the importance of facial injury (Jurmain, 1997, 1999) and nasal fractures in particular (Walker, 1997) have been recognized since we completed our earlier research. In addition, more rigorous radiographic analyses of forearm fracture as developed by Judd and Roberts (1999) and recently refined by Judd (2008) are important in understanding the etiopathogenesis of forearm injury in this population. The recent highly intriguing reports of perimortem bone modification, including probable prehistoric trophy taking in central California (Andrushko et al., 2005), stimulated us to reassess the collection to determine whether the CA-ALA-329 population showed similar evidence. The addition of new data, enhanced methodologies, and a comprehensive team approach allowed us to develop a research design with the following goals: (1) examine the patterning and frequency of interpersonal aggression in this population as revealed by the more specific distribution of lesions by anatomical location, sex, age, and temporal period; (2) document any correlation among the various skeletal indicators of aggression to assess the reliability of particular indicators, especially the cross-correlations of other indicators with forearm injury in the interpretation of so-called "parry fractures"; and (3) systematically compare the paleoepidemiology of this population with other well-controlled samples (most pertinently from California, but also from other regions of North America). While such comparable data on interpersonal aggression have not yet been widely reported, population-based comparisons of available datasets allow for more quantifiable, more accurate, and ultimately more testable hypotheses regarding the nature and prevalence of aggression through time and across space. Finally, we explore cultural explanations for variation in the expression and prevalence of markers of interpersonal aggression in prehistoric California samples in regard to possible resource competition and changing patterns of weapon use.

\section{ARCHAEOLOGICAL CONTEXT}

Originally classified a "shellmound" by Nelson (1909), CA-ALA-329 is actually a conspicuous earthen mound site with various amounts of shell mixed within its stratified soil deposits. The site is one of four closely clustered mounds located within the Coyote Hills approximately 20 miles north of San Jose adjacent to wetlands along the southeastern side of San Francisco Bay (see Fig. 1). In overall dimensions CA-ALA-329 is a large prehistoric mortuary mound, 12-15 feet high, consisting of approximately 20,900 cubic yards of stratified deposit. The site was partially excavated under controlled conditions by several institutions, including UC Berkeley, Stanford University, San Jose State University, and Hayward State University (Coberly, 1973; Leventhal, 1993; Wilson, 1993).

Of the 48,670 shell, bone and stone artifacts recovered from the San Jose State University excavations, a total of 44,210 (91\%) were directly associated with burials. Given only minimal post-depositional disturbance to the

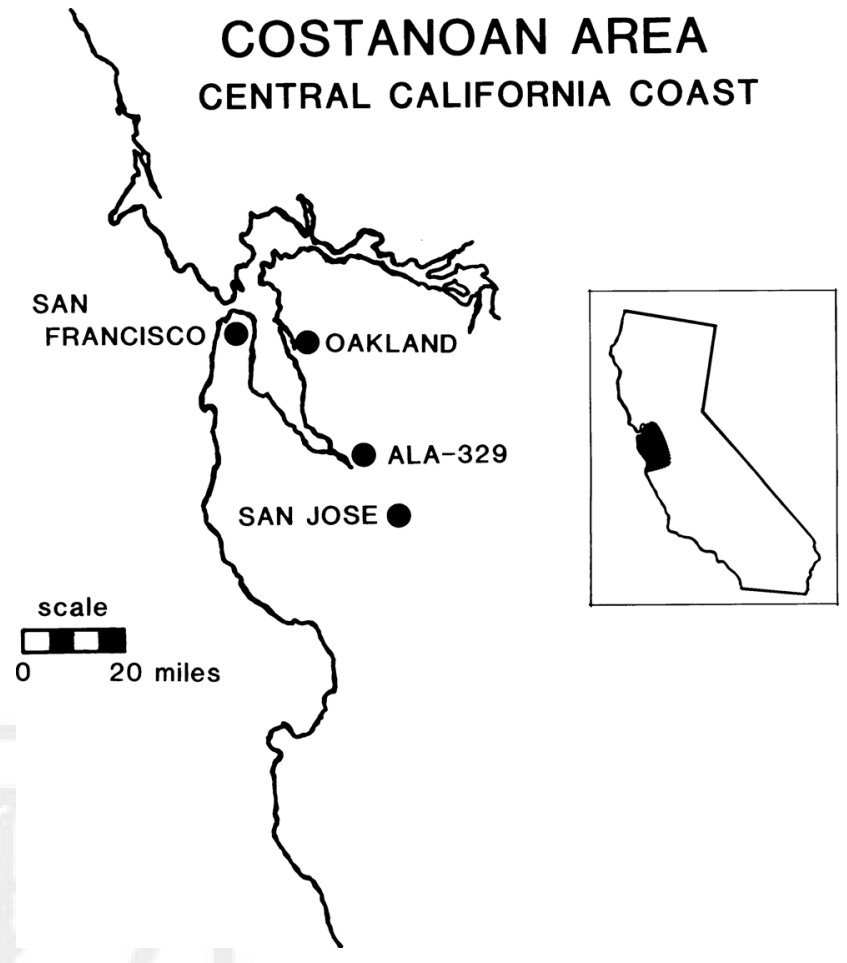

Fig. 1. Location of CA-ALA-329, southeastern San Francisco Bay, central California.

site, only $9 \%$ of artifacts were recovered from the mound matrix, and many of these were likely derived from disturbed burials (Yates, 1875; Coberly, 1973; Leventhal, 1993).

The chronology of the site has been well established through 45 radiocarbon dates, obsidian hydration, time sensitive artifacts (e.g., cut shell beads and pendants), and stratigraphic superposition that places the primary period of occupation from $\mathrm{AD} 500$ to the Protohistoric Period but prior to European contact (ca. 1769); there are, in addition, four interments dating prior to AD 500, including one dating to 200-100 BC (Leventhal, 1993, 2007; Groza, 2002)

The temporal sequence developed for prehistoric central California (Bennyhoff and Hughes 1987; Bennyhoff and Fredrickson, 1994) is used to seriate our sample. The two periods to which all of the burials are assigned include the Middle Period (beginning $500 \mathrm{BC}$ ) and Late Period (beginning $\sim A D$ 900). The Late Period is further divided into Phase I (AD 900-1500) and Phase II (AD 1500-1769). CA-ALA-329 represents primarily a Late Period occupation with the majority of burials dating after $\mathrm{AD} 500$.

Modern marshland communities were established in the southern San Francisco Bay Area by 2,000 BP, and marked a period of more stable local environmental conditions compared to the middle Holocene (West, 1993). Periods of reduced freshwater inflow into San Francisco Bay from the Sacramento-San Joaquin Delta are indicated by changes in salinity and pollen records, and correspond to drought conditions dating to ca. 3,000-2,500 BP and ca. 1,750-750 BP (Byrne et al., 2001). Although it is unclear to what degree these oscillating environmental conditions may have impacted prehistoric societies, Ingram (1998) and Lightfoot and Luby (2002) note 


\section{INTERPERSONAL AGGRESSION IN CENTRAL CALIFORNIA}

a reduction in the number of site components dating to the latter drought period, which roughly corresponds to the Medieval Climatic Anomaly (MCA). However, at CAALA-329, there is little evidence to suggest a disruption in the use of the site corresponding to the drought conditions of the MCA (Leventhal, 1993).

\section{MATERIALS AND METHODS}

The largest archaeological excavations were conducted from 1959 to 1968 by San Jose State University (SJSU) and Stanford University (SU) and retrieved approximately 442 individuals. Preservation was generally excellent, and approximately one-third of burials were found largely intact (see Fig. 2). A minimum of 298 individuals comprises the curated SJSU portion of the sample; these well-preserved materials form the core sample used in the reanalysis reported here. However, the 144 individuals excavated by Stanford University archaeological field crews were reinterred in 1992 prior to final passage and initial implementation of NAGPRA. Owing to Stanford University's insistence to repatriate and reinter these individuals, this portion of the sample is obviously no longer available for further study. Those data collected prior to reinterment are included in this study and, where appropriate, were further augmented by assessment of photographs and radiographs. Nevertheless, there are unavoidable limitations when doing various analyses and interpretations of our samples. For the Stanford University portion of the sample we were not

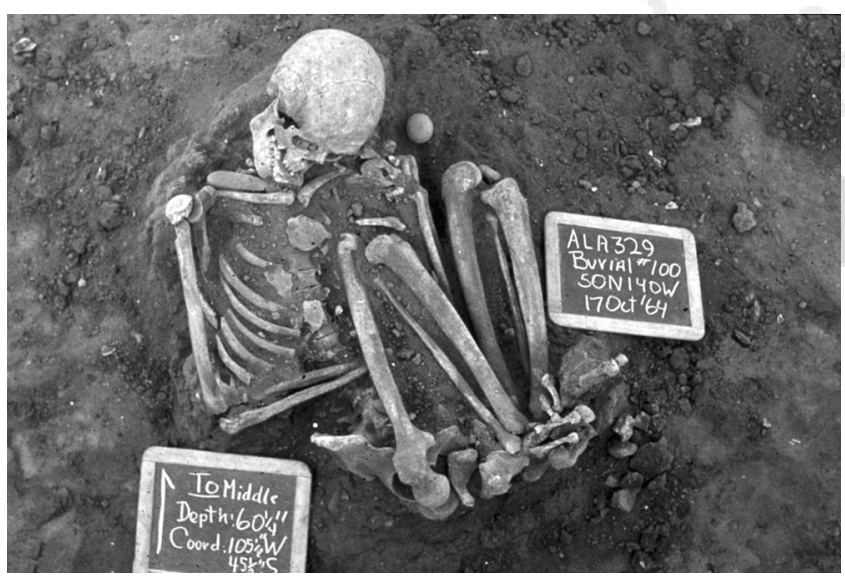

Fig. 2. Example of well preserved skeleton from CA-ALA329 , shown in situ during excavation. able to assess nasal fractures or do the necessary radiography to evaluate forearm injury. In addition, the evaluation of facial fracture in the SJSU and UCB samples included a more rigorous assessment of degree of preservation than was done in earlier work (Jurmain and Bellifemine, 1997). As a result of less complete control of relevant sample size, the Stanford individuals were not included in all analyses.

With this more rigorous control of sample representation, we could focus more confidently on individuals that preserved the relevant anatomical regions. For example, in the reanalysis of (combined) craniofacial injury in the SJSU and UCB materials, we included those individuals with complete cranial vaults and complete facial representation. In the text and tables this better controlled portion of the overall sample that includes only SJSU and UCB materials is referred as a "restricted sample." We have reconfigured the samples in this way to make the prevalence calculations more complete and likely more reliable. In a dilemma faced by all paleoepidemiologists, introducing more rigor to sample selection will almost surely reduce sample size, but, at the same time, will also reduce the likelihood of false negatives. Additionally, the sample that includes material from SJSU, UCB, and SU is used for analysis of cranial trauma, and in the text and tables is designated as the "full sample." These different samples are shown in Table 1 and are also noted as they are evaluated in this study.

In addition, as noted, we have recently expanded our sample to include skeletal material from CA-ALA-329 curated at the Phoebe A. Hearst Museum of Anthropology (UCB). This collection represents approximately 61 individuals. The total study sample thus comprises an estimated 503 individuals. For the two types of most diagnostic injuries indicative of interpersonal aggression (craniofacial and projectile wounds) all individuals were evaluated, including infants. However, since trauma resulting from interpersonal aggression is much more commonly found in adult skeletons, the majority of our analyses included only individuals reliably aged as $>15$ years $(N=342)$. Virtually all other paleoepidemiological studies of trauma/interpersonal aggression also focus on adult material, and our research design thus facilitates comparisons with other populations.

The available sample including cranial and postcranial remains used for analysis of projectile injury was composed of 158 males, 154 females, and 81 individuals of indeterminate sex (30 of whom were adults) (Table 1). Occasionally individuals younger than 16 can be victims of interpersonal aggression, and at CA-ALA-329, a juvenile aged 13-15 years had a cranial depression fracture. Thus, for some analyses we also include with the adults

TABLE 1. Skeletal samples from $C A-A L A-329^{a}$

\begin{tabular}{|c|c|c|c|c|c|c|c|c|c|c|c|c|c|c|c|c|}
\hline \multirow[b]{2}{*}{ Samples $^{b}$} & \multicolumn{4}{|c|}{ Projectile injury $^{c}$} & \multicolumn{4}{|c|}{ Cranial vault } & \multicolumn{4}{|c|}{ Facial } & \multicolumn{4}{|c|}{ Craniofacial $^{\mathrm{d}}$} \\
\hline & M & $\mathrm{F}$ & $\mathrm{I}^{\mathrm{e}}$ & Tot & $\mathrm{M}$ & $\mathrm{F}$ & I & Tot & $\overline{\mathrm{M}}$ & $\mathrm{F}$ & I & Tot & $\overline{\mathrm{M}}$ & $\mathrm{F}$ & I & Tot \\
\hline Full sample ${ }^{f}$ & 158 & 154 & 81 & 393 & 111 & 112 & 22 & 245 & 77 & 83 & 11 & 171 & 76 & 83 & 11 & 170 \\
\hline $\begin{array}{l}\text { Restricted sample: } \\
\text { SJSU, UCB }\end{array}$ & $\mathrm{NA}^{\mathrm{g}}$ & NA & NA & NA & 87 & 91 & 14 & 192 & 53 & 62 & 6 & 121 & 50 & 62 & 6 & 118 \\
\hline
\end{tabular}

a Includes individuals $>10$ years old (adolescents and adult age groups).

b Samples available used to assess each type of injury.

c All burials included, even fragmentary ones, that could be assigned to either "adolescent" or "adult" age categories.

d Combined sample preserving both face and vault.

e Indeterminate sex.

${ }^{\mathrm{f}}$ San Jose State University (SJSU), UC Berkeley (UCB), and Stanford (SU) materials.

${ }^{g}$ Not applicable. Restricted sample used only in analysis of vault, facial and combined craniofacial involvement. 
the juvenile portion of the sample, aged $10-15$ years $(N$ $=51$ ).

All individuals were aged and sexed using standard osteological criteria (Ubelaker, 1989; Buikstra and Ubelaker, 1994; Bass, 1995). The SJSU and SU portions of the sample were aged and sexed by R.J., while the UCB portion was evaluated by EJB. All criteria were analogous, except as noted below. Assessment of sex was augmented by metric analysis (Dittrick and Suchey, 1986). Given that the sample used was restricted to mature (or mostly mature) individuals, age was assessed using primarily pubic symphysis remodeling (Todd, 1920, 1921; Katz and Suchey, 1986; Brooks and Suchey, 1990), as well as auricular surface remodeling (Lovejoy et al., 1985), and in a few cases that lacked intact pelves (for the UCB portion of the sample), ectocranial cranial suture closure (Meindl and Lovejoy, 1985). For the adolescents and young adults, age at death was evaluated primarily on the basis of later stages of epiphyseal union.

Evaluation and differential diagnosis of osseous lesions were primarily macroscopic, and where appropriate, assisted by a hand lens and/or dissecting microscope. Radiography further assisted in evaluating all ambiguous lesions observed on gross examination as well as providing further data from survey radiographs of long bones for a large portion of the sample. All the radiographs were taken at the SJSU Student Health Center by X-ray technicians assisted by one of the authors (in a few cases from earlier research, such support was provided by other research assistants from the physical anthropology laboratory). In addition to approximately 200 radiographic plates used in prior analyses, we had 44 more radiographs taken, including approximately 25 used to assess the subcortical involvement in projectile injuries indicating degree of healing, and seven used to assess craniofacial bone remodeling Because the evaluation of forearm fractures is especially dependent on radiographic criteria, a further 12 plates were taken of ulnae and radii (all under the supervision of DD). A rigorous approach was employed following the methodology suggested by Grauer and Roberts (1996) and elaborated by Judd and Roberts (1999) and most recently by Judd (2008). Using an AmeriCorp LX 125 Collimator 3 Phase Generator Picker GX550, the images were taken on a 14 $\times 17^{\prime \prime}$ regular cassette at $40^{\prime \prime}$ on a table top X-ray machine; settings were calibrated at $42 \mathrm{kV}$ at $1.8 \mathrm{~mA}$.

With a team of multiple observers, it is crucial to ensure consistency in data collection to minimize interobserver error. Accordingly, specific team members undertook each of the individual osteological analyses. VB was the primary researcher who gathered the initial data on craniofacial involvement in the San Jose and Stanford University materials and also served as the lead researcher reevaluating cranial vault involvement in the SJSU sample.

A more rigorous and systematic evaluation of facial involvement was carried out by I.N. for the entire SJSU collection. I.N. and E.J.B. examined the UCB sample for vault and facial involvement following an identical protocol developed for the SJSU sample. RJ initially evaluated projectile point involvement on the San Jose and Stanford University materials. The SJSU subsample was reevaluated by M.A. and D.D. under the direct supervision of R.J. The UCB subsample was later fully evaluated by M.A. and D.D. Data from the Stanford University subsample was based entirely on the earlier analysis by R.J. Forearm involvement was performed by D.D. on the SJSU subsample. Although the Stanford University sample had been assessed macroscopically (by R.J.) using comparable methods, and in several cases using radiography, these data do not meet the more rigorous requirements of the current study. Thus, these materials, as well as those from UCB (where radiographic analysis has not yet been possible), are not included in our analysis of forearm fracture. Lastly, evidence of perimortem bone modification in the SJSU sample was evaluated by R.J.

Statistical comparisons of trauma prevalence were computed using chi-square tests, and Fisher's exact test was used when expected counts were less than five. Statistical significance was set at the $\alpha=0.05$ level.

\section{RESULTS}

In this study osteological evidence of interpersonal aggression involved evaluation of craniofacial fracture, projectile injury (most crucially, embedded obsidian projectiles/projectile fragments), forearm fracture, and perimortem bone modification.

\section{Craniofacial injury}

Among the most commonly used indicators of interpersonal aggression is craniofacial fracture. In the full sample of adults and adolescents (SJSU, UCB, and ST), 245 partial or complete crania were available for analysis (Table 1). A total of 15 individuals had evidence of healed or healing craniofacial fracture. Thirteen healed cranial vault lesions were found in eight individuals, of which six were located on the parietals, four on the frontal, and three on the occipital. There was little evidence of any lateral bias in vault involvement, with eight of the lesions on the right side and five on the left. In addition, nine cases of facial injury were observed, and included five nasal fractures, three of the zygomatic/ zygomatic arch, and one of the mandible. For the nonnasal fractures, three were on the right side and one on the left. In the 15 involved cases, two individuals showed both cranial vault and facial lesions. Statistically significant differences were found between the combined craniofacial injuries and the side on which they occur. Most of the lesions $(70 \%)$ are located on the right side $(P=$ $0.001)$.

The overall prevalence in the full sample of adult/adolescent cranial vault injury was $3.3 \%(N=245)$ (Table 2 ). When considering adults only ( $>15$ years), seven cases were found, yielding a prevalence of $3.1 \%(N=$ 225). For facial involvement specifically calculated from the more restricted sample (SJSU, UCB), all cases were in adults, with a prevalence of $6.1 \%(N=114)$. Combined adult craniofacial prevalence of both complete and incomplete crania was $9.0 \%(N=111)$.

The distribution of cranial injury by sex has often been reported and is of considerable interest. At CAALA-329 in the restricted sample the prevalence of facial involvement among males was more marked at $13.2 \%(N$ $=53)$, with no involvement in females $(N=62)$. This difference is highly significant $(P=0.004)$. Evaluating overall craniofacial involvement by sex also yielded a significant difference. Male prevalence was $20.0 \%(N=50)$, while female prevalence was $1.6 \%(N=62)(P=0.002)$ (Table 3). 
INTERPERSONAL AGGRESSION IN CENTRAL CALIFORNIA

TABLE 2. Craniofacial Injury and overall prevalence results

\begin{tabular}{|c|c|c|c|c|}
\hline Samples used & Region evaluated & Age & $N$ & Prevalence $(\%)$ \\
\hline \multirow{4}{*}{$\begin{array}{l}\text { Complete sample: } \\
\text { SJSU, UCB, SU }\end{array}$} & Cranial vault & Adult and adol. & 245 & 3.3 \\
\hline & & Adult & 225 & 3.1 \\
\hline & Face & Adult & 159 & 5.7 \\
\hline & Vault and face & Adult & 158 & 9.5 \\
\hline \multirow{3}{*}{$\begin{array}{l}\text { Restricted sample: } \\
\text { SJSU, UCB }\end{array}$} & Cranial vault & Adult & 177 & 2.8 \\
\hline & Face & Adult & 114 & 6.1 \\
\hline & Vault and face & Adult & 111 & 9.0 \\
\hline
\end{tabular}

TABLE 3. Craniofacial injury and adult prevalence by sex

\begin{tabular}{lccc}
\hline Region evaluated & $\begin{array}{c}\text { Samples } \\
\text { used }\end{array}$ & $\begin{array}{c}\text { Male, } \\
N(\%)\end{array}$ & $\begin{array}{c}\text { Female, } \\
N(\%)\end{array}$ \\
\hline Face & SJSU, UCB & $53(13.2)$ & $62(0.0)$ \\
Vault and face (combined) & SJSU, UCB & $50(20.0)$ & $62(1.6)$ \\
\hline
\end{tabular}

TABLE 4. Prevalence of projectile injury by temporal period

\begin{tabular}{lcc}
\hline Temporal period & $N$ & Prevalence (\%) \\
\hline Middle: 500 BC to AD 900 & 63 & 3.2 \\
Late Phase I: AD 900 to AD 1500) & 142 & 5.6 \\
Late Phase II: AD 1500 to AD 1769 & 111 & 3.6 \\
\hline
\end{tabular}

The age distribution of affected individuals in this (restricted) sample showed no significant difference between younger (aged 16-34) and older adults (35+) for vault, facial, or combined craniofacial involvement. While no significant temporal difference was observed among prevalence of facial and combined craniofacial trauma, a significant increase was found for vault involvement for the full sample between Late Period Phase I $(0.8 \%)$ and Late Period Phase II $(6.8 \%)(P=$ 0.05).

In addition to healed cranial trauma, three perimortem vault fractures also were diagnosed in this population $(N=192$, from the restricted sample). Because perimortem lesions are less diagnostic than healed ones, these cases are not included in any of the above prevalence calculations. Two of the perimortem victims were males and one female, and estimated age at death of all involved individuals was $>35$ years. As with healed craniofacial trauma, perimortem fractures showed clear predisposition for the right side. In two cases the fractures were located on the posterior right parietal, and one male had a fracture on the right temporal.

\section{Projectile injury}

Projectile injury is also quite common is this population with a total of 17 embedded points in 15 individuals. The overall prevalence in the combined adult sample of such injury is $4.4 \%(N=342)$. Of the individuals with projectile wounds, nine are males (showing a prevalence of $5.7 \% ; N=158$ ). Females are less commonly affected, with a prevalence of $1.9 \%(N=154)$. However, this difference does not attain statistical significance $(P=$ $0.139)$. It should be noted that three of the affected individuals are of indeterminate sex.

The age distribution of the projectile wounds reveals a significantly higher prevalence in young adults (16-34 years) than in older adults $(35+)$. Younger adults show almost five times the prevalence rate $(7.4 \%, N=148)$ compared with older adults $(1.5 \%, N=138)(P=0.15)$.

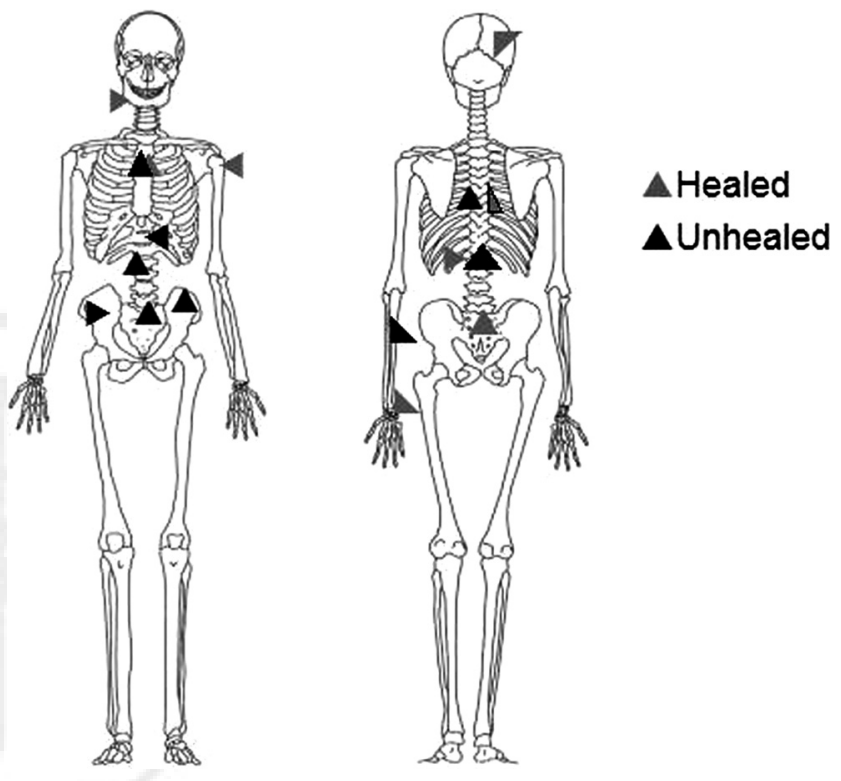

Fig. 3. Anatomical location of embedded projectile points in the CA-ALA-329 sample.

Some wounds appear not to be as serious and are well healed. In those three individuals with healed wounds in whom age could be estimated, the average age at death was 35.2 years. Perhaps more interesting is the age distribution of individuals with unhealed injuries. Among this group, we found an average age of only $23.4(N=$ $10)$, far younger than in those individuals with healed wounds.

Analysis of patterns of involvement of projectile injury by the three temporal periods of occupation at CA-ALA329 range from a low of $3.2 \%$ in the Middle Period to $5.6 \%$ in the Late Period, Phase I (Table 4). However, no temporal comparisons of the three periods approached statistical significance.

The anatomical location of projectile wounds is varied, with two embedded injuries of the skull (parietal, mandible), three of the upper limb (humerus/scapula, radius, ulna), two of the sternum (manubrium), eight of the vertebral column (ranging from T6 to L5), and two of the pelvis (ilium). From a general perspective of overall anatomical orientation, nine of the wounds are primarily anterior, while eight are primarily posterior (see Fig. 3). In terms of laterality, as expected, most wounds are on or near the midline. Only three injuries are more peripheral, all to the left upper limb. Since we can assume that there was some lethal intent, or at least a focused objective to hit the targeted individual, aiming at the thorax (or secondarily the head) was likely deliberate. The peripheral wounds were probably more unintentional, 
either due to imprecise aim or due to a limb being struck in the line of fire.

\section{Forearm injury}

Aspects of forearm fracture have been commonly used as indicators of interpersonal aggression. Most notably, ulnar fractures, particularly of the left side, have often been termed "parry fractures." For the combined SJSU and Stanford University samples, ulnar fractures show a prevalence by element of $5.2 \%(N=290)$, and radial fractures show a prevalence of $4.3 \%(N=301)$. In terms of laterality, there is only slightly greater involvement of the left ulna $(9 \mathrm{~L} / 6 \mathrm{R})$ and left radius $(8 \mathrm{~L} / 5 \mathrm{R})$.

Clinical data show forearm fractures can result either from falls or from deliberate direct blows. These are identified by fracture types, as either "transverse," thought to indicate direct force trauma from a blow or "oblique," considered more as an indication of indirect force caused by accidental falls. Because on gross examination these types of lesions can look identical and consequently make reliable differential diagnosis ambiguous, a further radiographic technique was used. Methodological recommendations by Grauer and Roberts (1996), Judd and Roberts (1999), Galloway (1999), and Judd (2008) suggest that radiographic analysis be used as a further step in diagnosing forearm fractures to provide visual assessment of fracture types.

When utilizing radiographs for diagnostic assessment of the SJSU CA-ALA-329 sample, results indicate a reinterpretation of previous analyses of these individuals (Jurmain, 1991). Based on the above methodological recommendations, this sample shows only one individual with evidence of direct force trauma to the left ulna resulting in a transverse fracture ostensibly associated with interpersonal aggression. This individual was a male between the ages of 31 and 35, with the fracture located on the diaphysis approximately two-thirds distal to the proximal end. The ipsilateral radius is present and unaffected. The remaining six ulnar fractures for both left and right involvement were oblique in nature indicating that these individuals most likely incurred their injuries from accidental causes.

Three of the individuals, two male and one female, had ipsilateral ulnar and radial fracture involvement. All involved individuals were aged $30+$ years, and the two affected males both showed a further complication of ununited healing. A third case of an ununited fracture was found in the left ulna of a female aged 21-30 years.

\section{Perimortem bone modification}

In central California there is also evidence of perimortem bone modification (i.e., alterations to fresh bone), in some cases highly suggestive of trophy taking (Andrushko et al., 2005). In order to assess perimortem modification, periarticular areas of the shoulder, elbow, wrist, hip, and knee were examined. A total of 183 adult individuals ( $>15$ years) drawn from the SJSU materials made up the available sample. In the upper limb 1,458 joint areas were assessed, and 712 separate areas in the lower limb were also observed. Of the combined 2,170 periarticular regions evaluated, no conclusive evidence of bone modification was found.

Patterns of interpersonal aggression can be further understood through analysis of correlations among the
TABLE 5. Correlations of skeletal indicators of interpersonal aggression

\begin{tabular}{|c|c|c|c|c|c|c|}
\hline Bur no. & Sex & Age & Vault & Face & Proj. & Forearm $^{a}$ \\
\hline SJSU $^{b} 14$ & M & $31-40$ & & + & & \\
\hline SJSU 19 & M & $35-45$ & & + & & \\
\hline SJSU 31 & $\mathrm{M}$ & $27-35$ & & & + & \\
\hline SJSU 40 & M & $25-35$ & + & & & \\
\hline SJSU 46 & $\mathrm{~F}$ & $35+$ & & & + & \\
\hline SJSU 50 & $\mathrm{M}$ & 31-39 & + & + & & \\
\hline SJSU 63 & M & $13-15$ & + & & & \\
\hline SJSU 87 & $\mathrm{~F}$ & $19-21$ & & & + & \\
\hline SJSU 90/91 & Indet & $14-18$ & & & + & \\
\hline SJSU 106 & M & $31-40$ & + & & & + \\
\hline SJSU 125 & M & $25-40$ & & & + & \\
\hline SJSU 162 & M & $20-22$ & & & + & \\
\hline SJSU 182 & $\mathrm{~F}$ & $21-35$ & + & & & \\
\hline SJSU 210 & Indet & Adult & & & + & \\
\hline SJSU 239 & M & $18-25$ & & & + & \\
\hline SJSU 243 & M & $35-44$ & + & + & & \\
\hline SJSU 260 & M & $21-25$ & & + & & \\
\hline $\mathrm{SU}^{\mathrm{c}} 9$ & $\mathrm{~F}$ & $25+$ & & + & & \\
\hline SU 70 & $\mathrm{M} ?$ & $15-17$ & & & + & \\
\hline SU 82 & Indet & Adult & & & + & \\
\hline SU 85 & $\mathrm{M}$ & $40+$ & + & & & \\
\hline SU 88 & $\mathrm{~F}$ & $17-21$ & & & + & \\
\hline SU 120 & $\mathrm{M}$ & $35-50$ & & + & & \\
\hline SU 126 & M & $35-44$ & & & + & \\
\hline $\mathrm{UCB}^{\mathrm{d}} 5324$ & M & $20-29$ & & + & & \\
\hline UCB 7071 & M & $30-39$ & & & + & \\
\hline UCB 7103 & M & 20-29 & & & + & \\
\hline UCB 7104 & $\mathrm{M}$ & $20-29$ & & & + & \\
\hline UCB $7114 \mathrm{G}$ & $\mathrm{M} ?$ & Adult & & + & & \\
\hline
\end{tabular}

a Forearm transverse ulnar fracture (radiographic diagnosis on San Jose State portion of collection only).

b San Jose State portion of collection.

c Stanford portion of collection.

d Berkeley portion of collection.

cases with craniofacial injury, projectile wounds, or particular manifestations of forearm fracture. (Note: There were no cases of perimortem bone modification).

As seen, 29 individuals have at least one osseous indicator of interpersonal aggression. However, there is little correlation among the various indicators. As noted, two individuals have evidence of both cranial vault and facial involvement. The only other instance of multiple traumatic involvement is an adult male who shows both cranial vault fracture and evidence of direct force trauma to his left ulna. In fact, this case is the only example of such forearm involvement found in this analysis.

\section{DISCUSSION Craniofacial injury}

Craniofacial injury at CA-ALA-329 is moderate in frequency and severity, as compared to other North American, and more specifically, to other California populations. At CA-ALA-329, in the restricted sample, adult crania show a $2.8 \%$ prevalence of vault injury. Another contemporaneous earthen mound site, CA-SCL-038, located approximately 10 miles south of CA-ALA-329, was also evaluated by the senior author (Jurmain, 2001). The prevalence of vault injury at CA-SCL-038 $(3.8 \% ; N$ $=159$ ) is very similar to that at CA-ALA-329. When comparing combined craniofacial involvement, the prevalence at CA-SCL-038 $(4.4 \% ; N=159)$ is lower than at CA-ALA-329 (9.0\%). All of this difference is due to a higher prevalence of facial injury at CA-ALA-329. Simi- 
lar levels of cranial vault injury $(2.7 \%)$ have been found by Newman (1957) in a skeletal series that consisted of several sites from the Central Valley, located to the northeast of the San Francisco Bay Area.

Skeletal research in southern California has shown a markedly higher prevalence of cranial vault fracture than found at CA-ALA-329 and other central California sites. Walker (1989) and Lambert $(1994,1997)$ systematically analyzed a very large skeletal series from the Santa Barbara Channel region. Walker reported overall population vault involvement at $19.4 \%(N=744)$. Lambert (1994) in a further, more expanded study, evaluated the paleoepidemiology of cranial vault fracture through a variety of controlled comparisons. Her adult sample showed a prevalence of $19.8 \%(N=663)$. When also including adolescents 10 years or older $(N=716)$, the prevalence was $19.0 \%$

Lambert also investigated patterns of cranial vault involvement by age and temporal period. Results showed increasing prevalence with age, peaking at $21.3 \%$ in older and mature adults ( $>26$ years) and paralleling the findings in our study.

The temporal patterning of cranial vault injuries among prehistoric Santa Barbara Channel populations is also most intriguing. Lambert's sample spanned 7,500 years. Prevalence was shown to be quite high in all periods, ranging from a low of $9.5 \%$ in an earlier portion of the sequence (ca. 3,500-1,400 BC) and peaking at $25.1 \%$ in the succeeding period (ca. 1,400 BC to AD 300).

Tyson (1977) analyzed a much smaller sample $(N=$ 49) from Baja California and found the highest degree of vault involvement $(30.6 \%)$ yet reported from a North American population. Clearly, cranial trauma was much more common in regions of southern California than has been found to the north in central California.

From other North American archaeological locales, where moderate levels of interpersonal aggression have been suggested, prevalence levels of vault injury similar to those in central California have also been reported. For example, Smith (2003) found a prevalence of $3.6 \%$ in Eastern Tennessee. The most extreme example comes from the Crow Creek site in South Dakota where $41 \%$ of crania showed perimortem trauma (Willey, 1990; Willey and Emerson, 1993). However, this population was massacred in a single attack, with most victims also being mutilated.

Numerous less systematic studies from North America have found similar levels of vault involvement to that in central California, varying between $2 \%$ and $5 \%$ prevalence in the American Southwest (Hooton, 1930; Stewart and Quade, 1969; Miles, 1975), Illinois (Morse, 1969), and Kentucky (Snow, 1948).

In addition, from elsewhere in the world, several recent well-controlled studies showed a high prevalence of cranial vault trauma ranging from $8 \%-29 \%$ (Standen and Arriaza, 2000; Lessa and Mendonço de Souza, 2004; Judd, 2006; Torres-Rouff and Costa Junqueira, 2006; Tung, 2007).

Evidence from vault lesions alone, or when combined as overall craniofacial involvement, can be highly informative regarding aspects of potentially violent behavior. Examining facial injury (including nasal involvement) separately can provide a further useful perspective. As noted, most researchers have not specifically recorded prevalence of facial injury, but some recent exceptions are notable (Owsley et al., 1994; Jurmain and Bellifemine, 1997; Walker, 1997; Standen and Arriaza,
2000; Jurmain, 2001; Judd, 2006; Torres-Rouff and Costa Junqueira, 2006).

It is particularly illuminating to look at sex-related patterns of facial involvement. In some archaeological samples, only minimal facial involvement was found and little variance between sexes has been observed (Standen and Arriaza, 2000; Jurmain, 2001; Judd, 2006).

By contrast, contemporary clinical data show a markedly higher prevalence of facial injury in males compared to females. A survey of 26 recent epidemiological studies of craniofacial trauma, collected from all major regions of the world in developing and developed countries, showed a range of proportional male involvement varying between $67 \%-91 \%$. When considering the 11 studies focusing solely on facial trauma, the proportion of male involvement varied from $75 \%-91 \%$ (Jurmain and Kilgore, 2007).

Moreover, data on African great apes also show significantly greater male involvement for facial injury (Jurmain and Kilgore, 1998, 2007). Thus, it is intriguing that prehistoric human samples generally have not shown a similar consistent pattern. The systematic data collection on CA-ALA-329 cranial material, however, does reveal a significant male preponderance of facial injury, but (as in apes) not such a notable difference for vault injuries. Overall the pattern at CA-ALA-329 conforms more closely to the wider dataset available among contemporary human populations and to that suggested even more generally in African apes. From a broad evolutionary perspective, the higher prevalence of male facial lesions matches theoretical expectations of high levels of male competition. In this light, Lambert's data (Lambert, 1994) showing significantly higher frontal involvement in males also supports this interpretation.

\section{Projectile injury}

The overall prevalence of craniofacial injury at CAALA-329 does not stand out on a general worldwide basis, and certainly not in comparison to prehistoric populations from southern California. However, when considering perforating projectile injury, this group shows a higher prevalence $(4.4 \%)$ than most other North American skeletal populations. There are few systematic reports of projectile injury that provide comparative prevalence data. From CA-SCL-038, a site located in the southern San Francisco Bay Area, four cases of embedded projectile injury were found in a large sample of 162 adults (2.5\%) (Jurmain, 2001). However, by far, the largest and the most systematic study is from southern California. Lambert $(1994,1997)$ found a $5.1 \%$ prevalence of embedded projectile wounds in an adult sample $(\mathrm{N}=$ 1,006) derived from a broad regional study encompassing several thousand years. Lambert (1994) examined the temporal distribution of projectile injuries, and found a remarkable pattern in interpersonal violence. For the five temporal periods considered, projectile injury varied from a low of $1.0 \%$ in the earliest period to a peak at $12.1 \%$ in sites dating primarily from $\mathrm{AD} 980$ to $\mathrm{AD} 1380$ (Lambert, personal communication).

Comparisons between central and southern California are complicated by the use of different chronological systems, but can be generally adjusted by referring to calendar years for site dates. There are, as expected, some difficulties, particularly since some sites span multiple time periods. While no statistically significant difference was found between any of the periods of occupation at 
CA-ALA-329, the peak involvement (5.6\%) occurred during the period dating from $\mathrm{AD} 900$ to $\mathrm{AD} 1500$.

Because largely overlapping correlations in estimated dates of occupation from the Santa Barbara Channel area can be established with those seen at CA-ALA-329, it is possible to compare projectile injury prevalence in the two regions during essentially the same time period. In the Santa Barbara region there was an unusually sharp spike of prevalence in adults, rising to $12.1 \%(N=$ 232 ), as compared to $5.6 \%$ during the same general time period at CA-ALA-329. The difference in prevalence between the two areas is even more pronounced when considering individual sites from the Santa Barbara Channel area, where in one mainland site population $(N$ $=21$ ) the frequency reached $23.8 \%$ (Lambert, personal communication).

Sex and age distributions in the large Santa Barbara Channel sample are also intriguing. Males showed a significantly greater $(2.7: 1)$ involvement than females, with the peak involvement for both sexes among adults aged 26-40. At CA-ALA-329 the pattern of involvement in adults shows a significantly higher prevalence in individuals younger than 35 years, following a similar distribution to that found by Lambert (1994). In terms of sex differences, the ratio of greater male involvement (3:1) at CA-ALA-329 is very similar to that observed in the Santa Barbara Channel region, although not statistically significant in our sample.

More than showing a very high frequency of such aggression in the Santa Barbara Channel Area, Lambert's data also reveal an unusually high intensity of such behavior. Among the victims, 30\% had more than one embedded projectile injury, and one unfortunate individual had five. Of the 15 affected individuals at CAALA-329, only two (13\%; each with two wounds) had multiple injuries.

Other studies from California and elsewhere have not been as systematic, and thus rarely provide adequate data and controls to allow calculation of prevalence. Nevertheless, the data reported from these other studies generally show lower rates of involvement than the $4.4 \%$ prevalence at CA-ALA-329. For example, Tenney's (1986) survey of central California materials curated at the Phoebe A. Hearst Museum of Anthropology identified 18 projectiles embedded in 13 individuals in a total sample of $>2,000$. Elsewhere in North America, a fairly high degree of projectile injury has been reported in Tennessee by Smith $(1996,1997)$ where she found seven cases of cranial wounds. Recently, Steadman (2008) reported two embedded projectiles in a large collection of 268 individuals from Illinois.

The observed rates of trauma at CA-ALA-329 would likely have contributed noticeably to increased morbidity and mortality in the population. Lambert $(1994,1997)$ and others have noted that the actual prevalence of serious penetrating projectile wounds to prehistoric groups must certainly have been considerably higher than indicated solely by projectiles found embedded in bone. No doubt this is the case, and Milner's (2005) perceptive analysis of medical records from 19th century arrow wound patients suggests only about one-third of projectile injuries impacted bone.

Of particular note, in southern California the peak prevalence of such serious injuries was far higher than has yet been documented in central California, or, for that matter, anywhere else in North America. The full extent of serious and oftentimes fatal wounds in some of the Santa Barbara Channel populations at certain times must have posed an extreme challenge to population sustainability.

Both the frequency and nature of projectile trauma are likely closely linked to changes in the effectiveness of available weapons. In this light, Lambert $(1994,2002)$ has noted that in southern California the introduction of the bow and arrow after $\mathrm{AD} 500$ may have contributed to increased levels of penetrating wounds, which, in turn, led to higher mortality.

The majority of projectile points recovered from CAALA-329 are primarily made of obsidian. During the Middle Period the principal weapon for hunting and warfare was the spear thrower (atlatl) used in conjunction with relatively large dart points. Some time around $\mathrm{AD} 1000$ to $\mathrm{AD}$ 1300, bow and arrow technology was widely adopted in the Bay Area. This technology, marked by the presence of smaller finely flaked Stockton Serrated obsidian points, replaced the heavier atlatl dart projectiles (Milliken et al., 2007, Rosenthal et al., 2007). While certainly still a provisional hypothesis, it is possible that after AD 900 such technological changes influenced the increase in projectile injury at CA-ALA-329.

\section{Forearm injury}

Interpretations of interpersonal aggression from patterns of forearm fracture have been controversial. Unlike projectile injury, which is unambiguous, or cranial injury (which is typically deliberate), the etiopathogenesis of forearm fracture is much less clear. Not surprisingly, clinical data show forearm fractures can result either from falls or from deliberate direct blows. In order to ascertain a more accurate diagnosis of various types of forearm injury and their presumed underlying etiology, we used recently suggested more precise radiographic techniques.

The results from this study suggest that forearm fracture in this population does not provide convincing diagnostic evidence relating to interpersonal aggression. Of the seven ulnar lesions evaluated radiographically, only one was of a transverse nature and thus suggestive of direct force trauma. Even in this case, it is not at all certain whether the injury was caused by a deliberate blow or the individual fell against a sharp object. However, it is perhaps notable that this adult male also was the victim of cranial vault injury, showing two healed depression fractures (one each to his frontal and occipital).

Because forearm injury lacks diagnostic specificity, its interpretation, even in this one suggestive case from CAALA-329, remains questionable. Gross analysis by itself appears not to be useful. More detailed radiographic assessment and specification of more rigorous diagnostic criteria have recently been clarified (Judd, 2008). Of further note, the one case of ulnar involvement in our sample does meet all four diagnostic criteria suggested by Judd. Nevertheless, evaluation of this method in our study or in others of a similar nature that rely solely on skeletal patterns observed in archaeological contexts obviously cannot provide a clear test of its validity. As a result, the oftentimes simplistic conclusions relating to "parry fractures" have led to over-diagnosis of this condition in the paleopathological literature. Until the etiopathogenesis of forearm fracture is more firmly established through more detailed and well-documented clinical series, its inclusion in evaluation of interpersonal aggression should be used with extreme caution. 


\section{Perimortem bone modification}

A recent influential report by Andrushko et al. (2005) on another site dating to the Middle Period (500 BC to $\mathrm{AD}$ 900) from the southern San Francisco Bay Area (CASCL-674) identified a further type of bone modification relating to interpersonal aggression. Several individuals were found lacking forearms/hands, two of whom also showed distal humeral perimortem modification. Further bioarchaeological evidence included the presence of drilled and polished radii and ulnae arguing for trophy taking as a likely behavior at this site.

A similar pattern of inferred trophy taking was encountered at two other Middle Period sites from the southern San Francisco Bay region. One of these (CAALA-328) is another earthen mound located adjacent to CA-ALA-329. Andrushko et al. (2005) identified five individuals from this site showing similar evidence of trophy taking as documented at CA-SCL-674. Additionally, at CA-SCL-478 six adult males exhibited evidence of perimortem trophy taking with four out of the six having upper limbs removed and three out of the six having severed lower limbs (Wiberg, 2002).

Moreover, less dramatic evidence of possible deliberate perimortem bone modification was also found at another Middle Period site further to the south in the Santa Clara Valley (Musladen et al., 1996). At this site (CASCL-732) possible bone modification was suggested in the elbow and/or hip in three individuals. But, unlike the clear pattern of bone changes and burial association at CA-SCL-674 or the evidence from CA-ALA-328 and CA-SCL-478, there was no evidence of trophy taking at CA-SCL-732.

\section{Interpreting patterns of interpersonal aggression in central California}

In contrast to the absence of trophy taking or other perimortem bone modification, after AD 500 at CA-ALA329 , projectile injury and craniofacial trauma apparently became more common. The introduction of the bow and arrow to central California around AD 1000 certainly could have influenced changing patterns of interpersonal aggression. New technology made more lethal forms of aggression possible and much more efficient at a distance.

While recognizing that generally interpersonal aggression in prehistoric California was quite high, it must be remembered that substantial variation is evident both geographically and temporally. In southern California the extremely high prevalence of both cranial vault injury and projectile wounds (the latter during one temporal period) has been interpreted by Lambert (1994, 1997) as related to resource depletion during extended periods of drought.

In the San Francisco Bay Area, current paleoenvironmental and archaeological research has also focused on how variation in availability of natural resources may have impacted the cultural history of local populations. Changes in resource exploitation have been suggested to be the result of macro-environmental changes, overhunting, or as a combination of several factors including technological shifts (Broughton 1994, 1999; Hildebrandt and Jones, 1992; Colten, 2002).

Nevertheless, for neither the San Francisco Bay Area nor the Santa Barbara Channel region has any consensus yet emerged regarding the primary factors influenc- ing temporal changes in environment, resource availability, or political organization. What seem more agreed upon are some highly visible changes in patterns of human skeletal trauma. The very high rates of interpersonal aggression in the Santa Barbara Channel region indicate some aspect of environmental stress and/or political competition likely exerted extraordinary pressures leading to an equally extraordinary increase in interpersonal aggression.

Studies of population health provide additional insight on possible causative factors of interpersonal aggression. In southern California, the peak in interpersonal violence coincided with a marked decline in health of local populations (Lambert, 1994). Increases in the prevalence of several markers of physiological stress in Santa Barbara Channel area populations, especially among islanders, has been mainly attributed to resource stress and unstable environmental conditions (MCA), which negatively affected availability of food and water resources (Lambert 1993, 1994; Lambert and Walker 1991). A significant decline in health over time was also found among prehistoric inhabitants of the Sacramento Valley (Bartelink, 2006). In this latter study, deterioration of health corresponded with predictions derived from resource intensification models.

In contrast to the Santa Barbara area and Sacramento Valley, studies of health in San Francisco Bay Area populations, and from CA-ALA-329 in particular, revealed little significant temporal difference in health status (Bartelink, 2006; Nechayev, 2007). Skeletal markers of stress, such as enamel hypoplasia, porotic hyperostosis, cribra orbitalia, and periosteal reactions did not demonstrate significant change over time (Bartelink, 2006; Nechayev, 2007). It is possible that resource depression due to population increase, intensified exploitation of lower-ranked resources, and environmental instability during the MCA were more successfully mitigated in the San Francisco Bay Area than in other regions of California for which comparable data exist. However, more data on health status bracketing the MCA period is needed to address this hypothesis.

\section{CONCLUSIONS}

Interpersonal aggression was quite common in prehistoric California, and such behavior persisted in different regions for several millennia. Temporal changes are apparent in central California, with specialized treatment of the dead as reflected in perimortem bone modification/trophy taking occurring more often among earlier populations. Later in time, and including the period encompassing almost all burials recovered at CA-ALA329 , the evidence for trophy taking declines sharply.

By contrast, the prevalence of other indicators of interpersonal aggression increased after $\mathrm{AD} 500$ showing moderate levels of craniofacial injury and high levels of projectile wounds (many of which appear to have been lethal). This patterning of osseous indicators of interpersonal aggression differs from that seen in southern California as best documented from the Santa Barbara Channel area. In this region cranial vault injury is far more frequent, while projectile injury showed a sharp increase during one temporal period that corresponds with the period at CA-ALA-329 of the highest prevalence of such injuries. Nevertheless, even at its highest level, these injuries are only about one-half as prevalent as found in southern California. 


\section{R. JURMAIN ET AL.}

CA-ALA-329 has yielded a large, well documented, and unusually well preserved skeletal sample. Nevertheless, it is just one site, and when compared to other more regionally based studies, provides only a fairly restricted temporal window into the past. In order to more fully understand the larger picture relating to interpersonal aggression and other bioarchaeological trends in central California, researchers need to emulate the successful models of regional research accomplished elsewhere in North America (Walker, 1989; Lambert, 1994; Smith, 1997) as well as some notable recent examples from other geographic areas (Lessa and Mendonça de Souza, 2004; Tung, 2007).

\section{ACKNOWLEDGMENTS}

We thank our two reviewers as well as the editorin-chief and the associate editor for their detailed and extremely useful comments. We are grateful to Dr. Tim D. White, Natasha Johnson, and the staff of the Phoebe A. Hearst Museum of Anthropology for their assistance with the UC Berkeley collections. We are appreciative of consultation provided by Alison Galloway and also thank Elizabeth Weiss for her generous sharing of her provisional data on facial fracture. René Schlice-Diehl at the San Jose State Student Health Center kindly provided assistance with radiography, and we gratefully acknowledge the continued support provided by Roger Elrod, Director of the Health Center. Lastly, we thank the Muwekma Ohlone Tribal Council leadership, and specifically Chairwoman Rosemary Cambra, for their support on this research and earlier CA-ALA-329 related research projects as well as past and current collaborations on other bioarchaeological projects under the Tribe's jurisdiction.

\section{LITERATURE CITED}

Andrushko VA, Latham KAS, Grady DB, Pastron AG, Walker PL. 2005. Bioarchaeological evidence for trophy taking in prehistoric central California. Am J Phys Anthropol 127:375-384.

Bartelink EJ. 2006. Resource intensification in pre-contact central California: a bioarchaeological perspective on diet and health patterns among hunter-gatherers from the lower Sacramento Valley and San Francisco Bay. Doctoral dissertation, Texas A\&M University, College Station, TX.

Bass WM. 1995. Human osteology. A laboratory and field manual, 4th ed. Columbia, Missouri: Missouri Archaeological Society. Special Publication No. 2.

Bennyhoff JA, Fredrickson DA. 1994. A proposed integrative taxonomic system for central California archaeology. In: Bennyhoff JA, Fredrickson DA, editors. Toward a new taxonomic framework for central California archaeology. Berkeley, CA: University of California Archaeological Research Facility. p 15-24.

Bennyhoff JA, Hughes RE. 1987. Shell bead and ornamental exchange networks between California and the western Great Basin, Anthropological Papers of the American Museum of Natural History No. 64. New York: American Museum of Natural History.

Brooks ST, Suchey JM. 1990. Skeletal age determination based on the os pubis: a comparison of the Acsádi-Nemeskéri and Suchey-Brooks methods. Hum Evol 5(3):227-238.

Broughton JM. 1994. Declines in mammalian foraging efficiency during the late Holocene, San Francisco Bay, California. J Anthropol Archaeol 13:371-401.

Broughton JM. 1999. Resource depression and intensification during the late Holocene, San Francisco Bay. Anthropological Records 32, University of California Publications. Berkeley: University of California Press.
Buikstra JE, Ubelaker DH, editors. 1994. Standards for data collection from human skeletal remains: Proceedings of a Seminar at the Field Museum of Natural History. Fayetteville, Arkansas: Arkansas Archeological Survey. Arkansas Archeological Survey Research Series No. 44.

Buzon R, Richman R. 2007. Traumatic injuries and imperialism: the effects of Egyptian colonial strategies at Tombos in upper Nubia. Am J Phys Anthropol 133:783-791.

Byrne R, Ingram BL, Starratt S, Malamud-Roam F, Collins JN, Conrad ME. 2001. Carbon-isotope, diatom, and pollen evidence for late Holocene salinity change in a brackish marsh in the San Francisco estuary. Quat Res 55:66-76.

Coberly M D. 1973. The archaeology of the Ryan Mound, Site ALA-329, a central California coastal village site. Archaeology Series 4. Colorado: University of Northern Colorado Museum of Anthropology.

Colten RH. 2002. Prehistoric marine mammal hunting in context: two western North American examples. Int J Osteoarchaeol 12:12-22.

Dawson L, Levy TE, Smith P. 2003. Evidence of interpersonal violence at the Chalcolith Village of Shiqmim (Israel). Int J Osteoarchaeol 13:115-119.

Dittrick J, Suchey JM. 1986. Sex determination of prehistoric central California skeletal remains using discriminant-analysis of the femur and humerus. Am J Phys Anthropol 70:3-9.

Galloway A. 1999. Broken bones: anthropological analysis of blunt force trauma. Springfield, IL: Charles C. Thomas.

Goodall J. 1986. The chimpanzees of Gombe. Cambridge: Cambridge University Press.

Grauer AL, Roberts CA. 1996. Paleoepidemiology, healing, and possible treatment of trauma in a medieval cemetery population of St. Helen-on-the-Walls, York, England. Am J Phys Anthropol 100:531-544.

Groza RG. 2002. An AMS chronology for central California Olivella shell beads. Master's Thesis, Department of Anthropology, San Francisco State University.

Hildebrandt WR, Jones TL. 1992. Evolution of marine mammal hunting: a view from the California and Oregon coasts. J Anthropol Archaeol 11:360-401.

Hooton EA. 1930. The Indians of Pecos Pueblo. New Haven: Yale University Press.

Ingram BL. 1998. Differences in radiocarbon age between shell and charcoal from a Holocene shellmound in northern California. Quat Res 49:102-110.

Judd MA. 2002. Ancient injury recidivism: an example from the Kerma Period of ancient Nubia. Int J Osteoarchaeol 12:89106.

Judd MA. 2004. Trauma in the city of Kerma: ancient versus modern injury patterns. Int J Osteoarchaeol 14:34-51.

Judd MA. 2006. Continuity of interpersonal violence between Nubian communities. Am J Phys Anthropol 131:324-333.

Judd MA. 2008. The parry problem. J Archaeol Sci 35:1658-1666.

Judd MA, Roberts CA. 1999. Fracture trauma in a medieval British farming village. Am J Phys Anthropol 109:229-243.

Jurmain RD. 1991. Paleoepidemiology of trauma in a central California population. In: Ortner DJ, Aufderheide AC, editors. Human paleopathology: current synthesis and future options. Washington, DC: Smithsonian Institution Press. p 241-248.

Jurmain RD. 1997. Skeletal evidence of trauma in African apes with special reference to the Gombe chimpanzees. Primates 38:1-14.

Jurmain RD. 1999. Stories from the skeleton. Behavioral reconstruction in human osteology. Amsterdam: Gordon and Breach.

Jurmain R. 2001. Paleoepidemiological patterns of trauma in a prehistoric population from central California. Am J Phys Anthropol 115:13-23.

Jurmain RD, Bellifemine VL. 1997. Patterns of cranial trauma in a prehistoric population from central California. Int $\mathrm{J}$ Osteoarchaeol 7:43-50.

Jurmain R, Kilgore L. 1998. Sex-related patterns of trauma in humans and African apes. In: Grauer AL Stuart-Macadam P, editors. Sex and gender in paleopathological perspective. Cambridge: Cambridge University Press. p 11-26. 


\section{INTERPERSONAL AGGRESSION IN CENTRAL CALIFORNIA}

Jurmain R, Kilgore L. 2007. Skeletal evidence of aggression in humans and African apes: an evolutionary perspective. Am J Phys Anthropol Suppl 44:139.

Katz D, Suchey JM. 1986. Age estimation of the male os pubis. Am J Phys Anthropol 69:427-435.

Keeley LH. 1996. War before civilization. New York: Oxford University Press.

Kilgore L, Jurmain R, Van Gerven DP. 1997. Paleoepidemiological patterns of trauma in a medieval Nubian skeletal population. Int J Osteoarchaeol 7:103-114.

Lambert PM. 1993. Health in prehistoric populations of the Santa Barbara Channel Islands. Am Antiq 58:509-522.

Lambert PM. 1994. War and peace on the western front: a study of violent conflict and its correlates in prehistoric huntergatherer societies of coastal southern California. PhD dissertation, University of California, Santa Barbara.

Lambert PM. 1997. Patterns of violence in prehistoric hunter gatherer societies of coastal southern California. In: Frayer DW, Martin DL, editors. Troubled times: violence and warfare in the past. Amsterdam: Gordon and Breach. p 77-109.

Lambert PM. 2002. The archaeology of war: a North American perspective. J Archaeol Res 10:207-241.

Lambert PM, Walker PL. 1991. Physical anthropological evidence for the evolution of social complexity in coastal Southern California. Antiq 65:963-973.

Lessa A, Mendonça de Souza S. 2004. Violence in the Atacama Desert during the Tiwanaku period: social tension? Int J Osteoarchaeol 14:374-388.

Leventhal AL. 1993. A reinterpretation of some Bay Area shell mound sites: a view from the mortuary complex from CAALA-329, the Ryan Mound. Master's thesis, Department of Social Sciences, San Jose State University, California.

Leventhal AL. 2007. Final results from the Lawrence Livermore National Laboratory Center for AMS dating on human collagen, charcoal and Olivella shell beads from prehistoric site CA-ALA-329. Results on file at the Anthropology Lab Facility, San Jose State University.

Lightfoot KG, Luby EM. 2002. Late Holocene in the San Francisco Bay area: temporal trends in the use and abandonment of shell mounds in the East Bay. In: Erlandson JM, Jones TL, editors. Catalysts to complexity: Late Holocene societies of the California coast. Cotsen Institute of Archaeology: Los Angeles. p 263-281.

Lovejoy CO, Heiple KG. 1981. Analysis of fractures in skeletal populations with an example from the Libben Site, Ottawa County, Ohio. Am J Phys Anthropol 55:529-541.

Lovejoy CO, Meindl RS, Pryzbeck TR, Mensforth RP. 1985. Chronological metamorphosis of the auricular surface of the ilium: a new method for the determination of adult skeletal age at death. Am J of Phys Anthropol 68:15-28.

Lovell NC. 1991. An evolutionary framework for assessing injury and illness in nonhuman primates. Yrbk Phys Anthropol 34:117-155.

Meindl RS, Lovejoy CO. 1985. Ectocranial suture closure: a revised method for the determination of skeletal age at death based on the lateral-anterior sutures. Am J Phys Anthropol 68:57-66.

Miles JS. 1975. Orthopedic problems of the Wetherill Mesa population, Mesa Verde National Park, Colorado. Washington, DC: US Department of the Interior, National Park Service.

Milliken R, Fitzgerald RT, Hylkema MG, Groza R, Origer T, Bieling DG, Leventhal A, Wiberg RS, Gottsfield A, Gillette D, Bellifemine V, Strother E, Cartier R, Fredrickson DA. 2007. Punctuated culture change in the San Francisco Bay Area. In: Jones TL, Klar KA, editors. California prehistory: colonization, culture and complexity. Walnut Creek, CA: AltaMira Press. p 99-123.

Milner GR. 2005. Nineteenth-century arrow wounds and perceptions of prehistoric warfare. Am Antiq 70:144-156.

Morse D. 1969. Ancient diseases in the Midwest. Springfield, IL: Illinois State Museum. Reports of Investigations, no 15.

Musladen A, Leventhal A, Morley S, Jurmain RD, Calleri D. 1996. Evidence of specialized burial treatment: an osteological sub-study. In: Cambra R, editor. Archaeological investigations at Kapahn UMUX (Three Wolves) Site, CA-SCL-732. Sonoma: Northwest Information Center, Sonoma State University. p 5.1-5.20.

Nechayev, I. 2007. A bioarchaeological study of health in the prehistoric population from CA-ALA-329. Master's thesis, Department of Social Sciences, San Jose State University, CA. Nelson NC. 1909. Shellmounds of the San Francisco Bay region. University of California: University of California Publications in American Archaeology and Ethnology (7)4.

Newman RW. 1957. A comparative analysis of prehistoric skeletal remains from the Lower Sacramento Valley. Berkeley, CA: University of California. University of California Archaeological Survey Report 39.

Ogilvie MD, Hilton CE. 2000. Ritualized violence in the prehistoric southwest. Int J Osteoarchaeol 10:27-48.

Owsley DW, Gill GW, Ousley SD. 1994. Biological effects of European contact on Easter Island. In: Larsen CS, Milner GR, editors. In the wake of contact. Biological responses to conquest. New York: Wiley-Liss. p 161-177.

Roksandic M, Djuric M, Rakocevic, Seguin K. 2006. Interpersonal violence at Lepenski Vir Mesolithic/Neolithic complex of the Iron Gates Gorge (Serbia-Romania). Am J Phys Anthropol 129:339-348.

Rosenthal JS, White GG, Sutton MQ. 2007. The Central Valley: a view from the catbird's seat. In: Jones TL, Klar KA, editors. California prehistory: colonization, culture and complexity. Walnut Creek, CA: AltaMira Press. p 147-163.

Smith MO. 1996. Parry fractures and female-directed interpersonal violence: implications from the Late Archaic Period of west Tennessee. Int J Osteoarchaeol 6:84-91.

Smith MO. 1997. Osteological indicators of warfare in the Archaic period of the Western Tennessee Valley. In: Frayer DW, Martin DL, editors. Troubled times: violence and warfare in the past. Amsterdam: Gordon and Breach. p 241-265.

Smith MO. 2003. Beyond palisades: the nature and frequency of late prehistoric deliberate violent trauma in Chickamauga Reservoir of east Tennessee. Am J Phys Anthropol 121:303318.

Snow CE. 1948. Indian Knoll skeletons of site Oh 2 Ohio County, Kentucky. Knoxville: University of Kentucky. University of Kentucky Reports in Anthropology no. 4. p 321-554.

Standen VG, Arriaza BT. 2000. Trauma in preceramic coastal populations of northern Chile: violence or occupational hazards? Am J Phys Anthropol 112:239-249.

Steadman DL. 2008. Warfare related trauma at Orendorf, a Middle Mississippian site in west-central Illinois. Am J Phys Anthropol 136:51-64.

Stewart TD, Quade LG. 1969. Lesions of the frontal bone in American Indians. Am J Phys Anthropol 30:89-110.

Tenney J. 1986. Trauma among early California populations [abstract]. Am J Phys Anthropol Suppl 69:271.

Todd TW. 1920. Age changes in the pubic bone I: the male White pubis. Am J Phys Anthropol 3:285-334.

Todd TW. 1921. Age changes in the pubis. Am J Phys Anthropol $4: 1-70$.

Torres-Rouff C, Costa Junqueira MA. 2006. Interpersonal violence in prehistoric San Pedro de Atacama, Chile: behavioral implications of environmental stress. Am J Phys Anthropol 130:60-70.

Tung TA. 2007. Trauma and violence in the Wari Empire of the Peruvian Andes: warfare, raids, and ritual fights. Am J Phys Anthropol 133:941-956.

Tyson RA. 1977. Historical accounts as aids to physical anthropology. Examples of head injury in Baja California. Pacif Coast Archaeol Soc Q 13:52-58.

Ubelaker DH. 1989. Human skeletal remains. Excavation, analysis, interpretation, 2nd ed. Washington, DC: Taraxacum.

Walker PL. 1989. Cranial injuries as evidence of violence in prehistoric southern California. Am J of Phys Anthropol 80:313323.

Walker PL. 1997. Wife beating, boxing, and broken noses: skeletal evidence for the cultural patterning of violence. In: Frayer DW, Martin DL, editors. Troubled times: violence and warfare in the past. Amsterdam: Gordon and Breach. p 145-163. 


\section{R. JURMAIN ET AL.}

Webb S. 1995. Palaeopathology of aboriginal Australians. Cambridge: Cambridge University Press.

West GJ. 1993.The Late Pleistocene-Holocene pollen record and prehistory of California's North Coast Ranges. In: White G, Mikkelsen P, Hildebrandt WR, Basgall ME, editors. There grows a green tree: papers in honor of David A. Fredrickson. Davis, CA: Center for Archaeological Research at Davis. p 219-235.

Wiberg RS. 2002. Archaeological investigations: Skyport Plaza Phase I (CA-SCL-478), San Jose, Santa Clara County, California. Report on file, Northwest Information Center, California Historical Resources Information System, Sonoma State University.

Willey P. 1990. Prehistoric warfare on the Great Plains. New York: Garland.

Willey P, Emerson T. 1993. The osteology and archaeology of the Crow Creek massacre. In: Tiffany J, editor. Prehistory and human ecology of the western prairies and northern plains. Plains Anthropologist 38(145) and Memoir 1993;27:227-269.

Williamson MA, Johnston CA, Symes SA, Schultz JJ. 2003. Interpersonal violence between 18th century Native Americans and Europeans in Ohio. Am J Phys Anthropol 122:113-122.

Wilson GB. 1993. The archaeological collection from CA-ALA329, the Ryan Mound, Alameda County, California. Salinas, CA: Coyote. Archives of California Prehistory No. 39.

Wood Jones F. 1910. Fractured bone and dislocations. In: EliotSmith G, Wood Jones F, editors. The archaeological survey of Nubia, Vol. II, Report on the human remains. Cairo: National Printing Department.

Wrangham R, Peterson D. 1996. Demonic males: apes and the origins of human violence. New York: Houghton Mifflin.

Yates L. 1875. The localities of mounds in Alameda County, Washington township. Alameda County Independent, July 3, p 10. 
AQ1: Please confirm that all author names are OK and are set with first name first, surname last. AQ2: Please check whether the units here are OK as typeset.

AQ3: Please check whether the "Willey and Emerson, 1993" reference is OK as edited.

AQ4: Please check the entry "0\%" under "Female, $N(\%)$." 